\title{
LXXI. Water radioactivity
}

\section{E.P. Adams}

To cite this article: E.P. Adams (1903) LXXI. Water radioactivity, Philosophical Magazine Series 6, 6:35, 563-569, DOI: 10.1080/14786440309463056

To link to this article: http://dx.doi.org/10.1080/14786440309463056

\section{曲 Published online: 15 Apr 2009.}

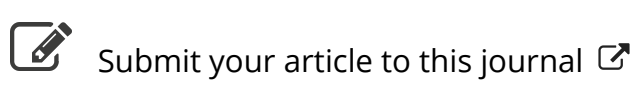

\footnotetext{
Џll Article views: 3
}

Q View related articles $\asymp$

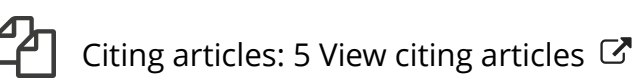




\section{$\left[\begin{array}{ll}563 & ]\end{array}\right.$}

LXXI. Water Radioactivity. By E. P. Adams*.

TTHE following is an account of some experiments made to determine the nature of the radioactive gas found in Cambridge tap-water by Prof. J. J. Thomson. It will be seen that this gas possesses properties remarkably similar to the emanation of radium.

Rutherford and Curie have shown that the radioactivity of the radium emanation decays according to the law

$$
\mathrm{I}=\mathrm{I}_{0} \epsilon^{-\lambda t} \text {, }
$$

where $\lambda$ is a constant over a wide range of conditions. It is therefore important to determine the rate of decay of the water radioactivity and to see whether a similar law holds.

A gold-leaf electroscope of the typedevised by C.T.R.Wilson has been used in most of these experiments, but instead of using sulphur insulation, a quartz rod, $10 \mathrm{~cm}$. long and $2.5 \mathrm{~mm}$. in diameter, was employed. The volume of the electroscope was about 200 c.c. The electroscope was charged to 200 volts, and the movement of the gold-leaf read by means of a microscope containing a scale in the eyepiece. The gases to be studied were admitted directly into the electroscope, which was connected to a Toepler pump, through a tightly-packed plug of glass-wool and a phosphorus-pentoxide drying-bulb.

\section{Rate of Decay of the Radioactivity.}

Water direct from a tap was passed through a copper tube which was placed in a combustion furnace, so that the water was thorougilly boiled on going through the tube. The gas thus driven out of the water was collected in a bottle which stood in a trough through which a stream of cold water continually circulated. In this way all the gas from a large volume of water could be quickly collected, and the radioactivity obtained in a very concentrated form. Sufficient gas was collected to fill the electroscope to atmospheric pressure. Readings of the rate of movement of the goldleaf were taken from time to time in order to get the rate at which the radioactivity decayed. Immediately after the gas was introduced into the electroscope, the leak was at the rate of 17 divisions per minute. This gradually increased for about two hours, after which it began to decrease slowly. The time required for the gold-leat to move over the same 30 divisions of the scale was determined each time, so that

* Communicated by Prof. J. J. Thomson, F.R.S. 
the sensitiveness was the same at each reading. The following table gives the results, beginning at the time when the maximum conductivity is reached:-

$\begin{array}{cccc}\text { Hours. } & \begin{array}{c}\text { Time to leak } 30 \text { divisions } \\ \text { in seconds. }\end{array} & \text { Reciprocals. } & 1 / \lambda . \\ 0 & 53 \cdot 2 & 188 & 366,000 \\ 16 \cdot 7 & 62 \cdot 7 & 160 & 401,000 \\ 40 \cdot 4 & 77 \cdot 6 & 129 & 444,000 \\ 64 \cdot 8 & 92 \cdot 7 & 108 & 381,000 \\ 88 \cdot 9 & 116 \cdot 3 & 86 & 372,000 \\ 139 \cdot 6 & 190 \cdot 0 & 53 & 573,000 \\ 160 \cdot 8 & 217 \cdot 9 & 46 & \end{array}$

The accompanying figure is plotted from the above table. The ordinates are the numbers in the third column, which are proportional to the conductivity of the gas, and the abscissæ are the times in hours.

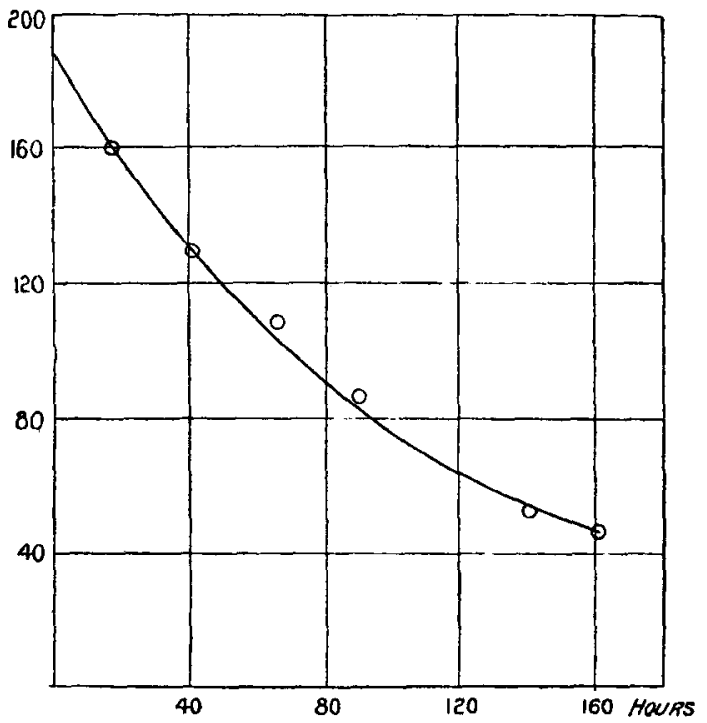

Assuming, as in the case of radium emanation, that the decay of the radioactivity can be represented by the formula

$$
\mathrm{I}=\mathrm{I}_{0} \epsilon^{-\lambda t} \text {, }
$$

the values of $1 / \lambda$ corresponding to the successive intervals are given in the fourth column of the above table. The time in this formula is expressed in seconds. Giving these 
values of $1 / \lambda$ weights proportional to the corresponding intervals, we get for the mean value

$$
1 / \lambda=425,000 \text {. }
$$

For radium emanation Rutherford gets

$$
1 / \lambda=463,000 \text {, }
$$

while Curie gets for the same

$$
1 / \lambda=497,000 \text {. }
$$

The value of $\lambda$ obtained thus for tap-water is in sufficiently good agreement with that obtained for radium emanation to make it very probable that the former is actually due to radium emanation.

Similar results have been obtained for air which has been thoroughly bubbled through tap-water, so that it seems that the conductivity produced in air by bubbling it through tapwater is due to the same cause as the conductivity of the dissolved gases in water.

\section{Absorption of Radium Emanation by Water.}

According to Rutherford radium emanation passes unchanged through water. But experiments were made to see whether some of the emanation, if only a very small proportion of it, was not absorbed by the water. This was done as follows:-

A weak solution of a radium compound was prepared, using distilled water which had been thoroughly boiled to expel all air. Air was then bubbled through the radium solution, having first passed through a tight plug of glasswool. From the radium solution the air passed through another tight plug of glass-wool, and then throngh a large bottle of thoroughly boiled distilled water. This was allowed to go on for three hours. At the end of this time air was blown into the bottle to sweep out thoroughly all of the radium emanation which remained above the surface of the water. Some of the water was then poured into a flask of about a litre capacity, provided with a rubber stopper with two holes, through one of which a glass tube passed to the bottom of the flask, while through the other a glass tube passed just through the stopper. 'l'he water was then boiled, and at the same time air from the room bubbled through it into a gas-holder. In this way all the dissolved gas and emanation, if any, was collected in the gas-holder. From the gas-holder the air was introdueed into the electroscope. Before this air was put in, when the electroscope was filled Phil. Mag. S. 6. Vol. 6. No. 35. Nov. 1903. 2 P 
with dry air from the room, the leak in the elcctroscope was at the rate of 0.5 division per minute. But with the air boiled out of water through which radium emanation had passed, the rate increased to 10 divisions per minute, and after abcut two hours it increased to 18 divisions per minute. It then began to decrease. On allowing the same sample of water to stand for several days, and again testing the air drawn through it as above, it was found that the rate of leak was the same as for air taken directly from the room. This shows conclusively that a small amount of radium emanation is absorbed hy water, and that the effect observed is not due to radium carried over in spray from the radium solntion. The glass-wool plug stopped all of that.

When the same volume of water direct from the tap is tested in the above way, the maximum rate of leak is about 2 divisions per minute. But this varies considerably at different times. Hence a very small quantity of radinm emanation dissolved in water would be sufficient to account for this.

Equal volumes of water containing the emanation in solution were tested from day to day to see whether the radioactivity decayed at the same rate in solution. It was found that the decay was considerably greater than for emanation kept in a closed vessel. The reason for this is that the decay is due to two causes: first, the decay in radioactivity of the emanation itself; and second, the escape of emanation from the solution. But a sample of water containing emanation in solution, when kept closed so that none of the emanation can escape, is found to decay at the same rate as emanation which is kept in a closed vessel.

But an important difference his been found between distilled water containing radium emanation in solution and tap-water. After the former has been thoroughly boiled so as to drive out all the emanation, it entirely loses its radioactivity, and on letting it stand for any length of time, and again testing the air drawn through the boiling water, this air is found to have no greater conductivity than air taken direct from the room. But with tap-water it is different. It is impossible to get rid of the radioactivity entirely by boiling the water so as to drive out all the dissolved gases. A minute trace remains. In fact, tap-water behaves as if it contained, in addition to dissolved emanation, an extremely minute quantity of a radium salt in solution. All attempts to evaporate a large quantity of water to dryuess, and to find any radioactivity in the solid residue, have so far failed. But the evidence for the presence of the radioactive salt is 
indirect. If a flask of tap-water is closed up air-tight, and allowed to stand for several days, it is found that the rate of decay of its radioactivity is considerably less than that of the gas driven out of it; in fact, on one or two occasions the radioactivity has actually increased on standing. This can be explained only by assuming that there is a continuous production of a radioactive emanation in the water. Further, tap-water is found to partially recover its radioactivity on standing after it has been thoroughly boiled, but never to its original value. In general, the recovery has been to about one-tenth of its original value.

\section{Induced Radioactivity.}

Just as radium emanation possesses the power of inducing radioactivity on bodies immersed in it, so the radioactive gas from water possesses the same property. To this is due the fact that when the gas is introduced into the electroscope the rate of leak increases for a time before it begins to decrease. The rate of decay of this induced radioactivity is the same when produced by the gas from tap-water as when produced by radium emanation. That is, it decays according to an exponential law, such that it falls to half its value in about 35 minutes.

This induced radioactivity is greater on a negatively charged conductor than on a positively charged one. When a conductor is not charged, there appears to be no induced radioactivity. When charged positively or negatively, the amount of induced radioactivity is at first proportional to the absolute value of the potential, and approaches a limiting value with high potentials. The rate of decay is the same for the induced radioactivity, whether produced by positive or negative electrification.

Experiments on induced radioactivity were made with air that had been circulated through water several times by passing through a water-pump. In this way the conductivity of the air in a large tank could be increased to about 80 times its normal value. Metal rods were suspended in this tank, and these could be charged to any desired potential. They were taken out after a definite time and suspended in another tank filled with ordinary air, and the current through this second tank, when the rod was connected to a quadrant electrometer, and the tank to a battery, compared with a similar rod which had not been made radioactive. In every case the voltage applied to the testing-tank was sufficient to give the saturation current. After each test the brass rod $2 \mathrm{P} 2$ 
was thoroughly sand-papered so as to remove all the induced radioactivity. The following table gives the relative amounts of induced radioactivity of a brass rod when charged to different potentials for the same length of time:-

$\begin{array}{cc}\text { Charged for } 10 \text { minutes at } & \text { Induced Radioactivity. } \\ -1000 \text { volts } & 32 \\ -800 & 28 \\ -600 & 23 \\ -400 & 18 \\ -200 & 12 \\ +1000 & 5 \\ +800 & 4 \cdot 5 \\ +600 & 3 \cdot 5 \\ +400 & 3 \cdot 0 \\ +200 & 2 \cdot 0 \\ 0 & 0\end{array}$

To compare this with the effect of radium emanation, air was drawn through a weak solution of a radium compound into a closed brass cylinder of about 8 litres capacity, in which a brass rod could be suspended and charged to any desired potential. The rod was then tested for radioactivity in another similar vessel filled with room air, the rod being connected to the electrometer and the eylinder to the battery. The following results give the magnitude of the effect:-

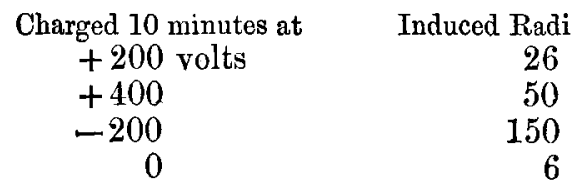

It is thus seen that the induced radioactivity due to radium emanation on a rod at 0 potential is only about one-eighth of that on a rod at +400 volts. But in the case of the gas from water, this would have been too small an amount to measure. This probably accounts for the fact that with the radioactive gas from water it has not been possible to observe any induced radioactivity on a conductor at 0 potential. It is also seen that for the induced radioactivity due to both radium emanation and the water radioactivity, the effects are about six times as great for a negatively charged conductor as for a positively charged one.

\section{Conclusion.}

The above results lead to the view that the water radioactivity is due to a substance very similar to, if not identical 
with, the emanation of radium, which is dissolved in the water. So far there is no indication of the presence of a sulficient amount of an emanating substance present in the water to account for the effects observed. The greater part of the emanation must be supposed due to radioactive emanating substances distributed near the source of the water.

It is a pleasure to express my sincere thanks to Prof. Thomson for the continual interest he has shown and help he has given during the course of this work.

Cavendish Laboratory, July 1903.

LXXII. Preliminary Note on the Effect of Pressure upon Arc Spectra. By J. E. Petavel and R. S. Hutton*.

[Plate XXV.]

\section{Introduction.}

$\mathrm{I}^{\mathrm{N}}$ the course of an investigation on the effect of high gaseous pressures upon the chemical reactions occurring at the temperature of the electric furnace, it was found advisable to make experiments with electrodes of different materials ; the spectra as observed visually seeming to show some points of interest, the brief investigation of the subject herein described was undertaken. The shift of the spectrum lines caused by pressure has already been carefully investigated by Humphreys, Mohler, Jewell, and others $\dagger$. A higher dispersion than that available in our experiments would be necessary to add anything further to this side of the question, which, therefore, we do not propose to deal with. In general, such results as are given and the explanations proposed must be regarded as preliminary in character; but it is hoped that before long the work will be continued in the Physical Laboratories of the Owens College.

The apparatus consisted of a strong steel enclosure, suitable for withstanding pressures up to 450 atmospheres, having an internal diameter of 11 inches and a capacity of about 20 litres. The electrodes, which were much larger than is usual for such work, varied in diameter from $\frac{1}{4}$ inch to 2 inches, they were supported by feeding rods passing air-tight through stuffing boxes, and capable of adjustment by a powerful screw gear. Apart from the usual valves for admission or circulation of gases under pressure, the apparatus is provided with

* Communicated by Prof. Arthur Schuster, F.R.S.

† Jewell, Astrophys. Journ. iii. p. 89 (1896); Humphreys and Mohler, Astrophys. Journ. iii. p. 114 (1896); Mohler, Astrophys. Journ. iv. p. 175 (1896); Humphreys, Astrophys. Journ. iv. p. 249 (1896), ri. p. 169 (1897). 